\title{
UMA REFLEXÃO FILOSÓFICA SOBRE A MEDIAÇÃO DA INFORMAÇÃO NA \\ BIBLIOTECONOMIA: OS PRESSUPOSTOS DO “O--QUE-É-SER- NO ATTO DE MEDIAR ENTRE A RACIONALIDADE E A CONCEPÇÃO REPRESENTACIONISTA DA INFORMAÇÃO”
}

\author{
Jetur Lima de Castro \\ Orientando \\ Mestrando em Ciências da Comunicação - PPGCOM - UFPA \\ jetur.er@gmail.com
}

Luiz Eduardo Ferreira da Silva

Orientador

Doutor em Ciência da Informação

Professor Adjunto do curso de Arquivologia - UFPB

LuizEduardo.ufpb@gmail.com

\section{Resumo}

Proporciona o exercício da interpretação e reflexão acerca da mediação da informação na Biblioteconomia, sobretudo, na busca de indícios e pistas para construir concepções teóricas por meio das ações comunicativas. Investiga a aplicabilidade da Mediação da Informação na Biblioteconomia a partir do fundamento epistemológico de Habermas com a teoria crítica e Dretske sob à luz da Filosofia da Informação, com o auxílio da Ciência da Informação. Dispõe-se de uma pesquisa teórica, na qual procura compreender de forma crítica e interpretativa o cenário biblioteconômico, mediante a discussão em relação à mediação da informação enquanto fenômeno (emancipatório). Por intermédio da hermenêutica crítica, buscou-se através dos indícios interpretativos encontrar as pistas para a incerteza epistemológica na Biblioteconomia, no contexto da mediação da informação. Os resultados indiciários e interpretativos demonstram que a mediação da informação na biblioteconomia é dominada pela racionalidade instrumental da técnica que, por sua vez, precisa passar pelo plano das ações comunicativas e emancipatórias. Por fim, conclui-se que a mediação da informação na Biblioteconomia necessita de questionamentos teóricos, a fim de anunciar e consolidar com um olhar crítico as "novas" relações possíveis de debate em torno da mediação, para que os reflexos comunicativos possam transcender as políticas da razão instrumental (ideologia da técnica), com a intenção de produzir agenciamentos e ações coletivas emancipatórias no ambiente das bibliotecas e, por assim, reconstruir as práticas de ressignificação da mediação.

Palavras-chave: Mediação. Biblioteconomia. Ação comunicativa. Percepção-ação. Emancipação. 